\title{
A CONTRIBUIÇÃO DA HERMENÊUTICA E DA FILOSOFIA DA LINGUAGEM NA ANÁLISE E FUNDAMENTAÇÃO DA INTERPRETAÇÃO E ALTERAÇÃO DO PRENOME
}

http://dx.doi.org/10.21527/2176-6622.2020.54.300-310

Recebido em: 7/10/2019

Modificações solicitadas em: 31/7/2020

Aceito em: 1ㅇ/9/2020

Raquel Fabiana Lopes Sparemberger

Doutorado e Mestrado em Direito pela Universidade Federal do Paraná - UFPR. Pós-Doutoramento em Direito pela Universidade Federal de Santa Catarina - UFSC. Graduação em Direito pela Universidade Regional do Noroeste do Estado do Rio Grande do Sul - Unijuí (1995). Professora-associada da Universidade Federal do Rio Grande - Furg. Professora dos cursos de Graduação e do Programa de Mestrado em Direito da Faculdade de Direito da Fundação Escola Superior do Ministério Público - FMP/RS. Tem experiência na área de Direito, com ênfase em Teoria Geral do Direito, Direito Constitucional, Direito Ambiental e Direitos Humanos, América Latina e Questões Decoloniais. Professora pesquisadora do CNPq e Fapergs. Pesquisadora do Grupo de Pesquisa Tutelas à efetivação dos direitos indisponíveis, Linha Tutelas à efetivação de Direitos Públicos Incondicionados. Grupo de Pesquisa: Sociedade da informação e "Fake Democracy": os riscos à liberdade de expressão e à democracia constitucional - FMP-RS. Responsável pelo Grupo de Estudos da Furg sobre Direito constitucional, violência e crise migratória. http://lattes.cnpq.br/1275535624435246. https://orcid.org/0000-0001-9366-9237. fabiana7778@hotmail.com

Giorgio Eduardo Bonezzi

Graduando do curso de Direito da Universidade Federal do Rio Grande - Furg. http://lattes.cnpq br/6034110099975970. https://orcid.org/0000-0002-6832-5608. giorgio.eduardobonezzi1@gmail.com

Jaime John

Professor-assistente da Faculdade de Direito da Universidade Federal do Rio Grande - Furg. Mestrado em Filosofia pela Pontifícia Universidade Católica do Rio Grande do Sul (1989). http://lattes.cnpq.br/0204133062487350. https://orcid.org/0000-0002-0869-4970. jaimejohn@terra.com.br

\section{RESUMO}

O presente trabalho tem por objetivo analisar e fundamentar, a partir de estudos linguísticos e interpretativos, a necessidade e a possibilidade de alteração do prenome no registro civil. Para tanto, recorreu-se às bases filosóficas de especulação sobre a real possibilidade de conhecimento dos fenômenos, método pelo qual se almeja compreender qual a função da linguagem nesse processo de inteligibilidade e quais seus fatores condicionantes. Destarte, tudo isso serve para, sem a intenção de esgotamento do debate, intentar a elucidação de fato tão complexo como é a alteração do prenome, não apenas pelo viés normativo, mas, antes, considerando e fundamentando-se nos pilares sobre os quais se erige o conhecimento. Por fim, traz-se à baila uma decisão do Supremo Tribunal Federal sobre este tema, de modo a concretizar as teorias estudadas. $O$ método de abordagem é o indutivo e a técnica de pesquisa é a bibliográfica.

Palavras-chave: Hermenêutica. Linguística. Alteração do prenome. Filosofia da linguagem. Direito civil.

\section{CONTRIBUTION OF HERMENEUTICS AND THE PHILOSOPHY OF LANGUAGE IN THE ANALYSIS AND FOUNDATION OF INTERPRETATION AND AMENDMENT OF PRENAME}

\section{ABSTRACT}

This work aims to analyze and to base, based on linguistic and interpretative studies, the necessity and possibility of changing the first name in the civil registry. In order to do so, we resort to the philosophical bases of speculation on the real possibility of knowledge of phenomena, a method by which one intends to understand the function of language in this process of intelligibility and its determinants. Thus, all this serves, without the intention of exhaustion of the debate, to try to elucidate a fact as complex as the change of the name, not only by the normative bias, but considering and basing itself on the pillars on which it erects knowledge. Finally, a decision of the Federal Supreme Court is presented on this subject, in order to concretize the theories studied. The method of approach is the inductive one and the research technique is the bibliographical one.

Keywords: Hermeneutics. Linguistics. Changing the first name. Philosophy of language. Civil right.

\section{SUMÁRIO}

1 Introdução. 20 processo dialético de conhecimento e a ação de conceituar. 2.10 lugar da linguagem. 3 Língua e cultura: a linguagem enquanto reflexo cultural e psicológico de uma sociedade. 3.1 Momento de deriva. 4 Linguagem em movimento: reestruturação de conceitos e interesses linguístico-sociais. 4.1 Humboldt e a Cosmovisão Linguística: a contribuição para a discussão sobre a alteração do prenome no registro civil. 5 Círculo hermenêutico e a interpretação de seres históricos. 6 Jurisprudência - análise da ação direta de inconstitucionalidade 4275 do supremo tribunal federal. 7 Conclusão. 8 Referências. 
O modo como vivenciamos uns aos outros, como vivenciamos as tradições históricas, as ocorrências naturais de nossa existência e do nosso mundo, é isso que forma um universo verdadeiramente hermenêutico, no qual não estamos encerrados como barreiras intransponíveis, mas para o qual estamos abertos (GADAMER, 1999).

\section{INTRODUÇÃO}

Este estudo tem como marco inicial duas indagações, a saber: (i) Por que fixamos determinados nomes a um certo grupo de pessoas e não a outros e como realizamos esse ato interpretativo? e (ii) O que condiciona alguém que, ao mudar de sexo, busca, também, a possibilidade de alteração civil do prenome e qual deve ser a resposta jurídica? Por esse viés, agregamos ao referido problema as questões jurídicas nele envoltas, de modo que não apenas se buscou esclarecer as questões histórico-linguísticas, mas, também, qual seria a posição defendida pelo direito diante dessa situação, e, ao final, analisou-se uma decisão do Supremo Tribunal Federal sobre a referida temática; fizemo-lo com o fito de reificar aquilo que foi, anteriormente, apresentado como teoria.

Destarte, esta pesquisa é importante, pois auxilia no entendimento mais complexo - ou na aproximação desse - a respeito das variações sociais, culturais e linguísticas e, portanto, no que deve o direito fazer quanto a isso. Por essa razão, buscou-se interdisciplinar auxílio para a abordagem feita, de maneira a não tornar simples ou simplório um fenômeno altamente complexo, diversificado e ramificado, como é o da discussão de gênero, tanto no âmbito linguístico quanto no social.

Nessa perspectiva, o estudo dividiu-se em três partes de exposição e discussão: (i) em um primeiro momento buscou-se, com o aporte teórico de Jean Paul Sartre (2004), Michel Villey (2003) e Johannes Hessen (1964), identificar as nuances próprias do processo de conhecimento e aquilo que disso resulta, isto é, o conceito - ou a ação de conceituar que parte do sujeito. Ainda nesse viés, fitando corroborar o papel fundamental da linguagem nessa sucessão de atos cognitivos e tendo firmado as bases de entendimento a respeito do conhecimento dos objetos e da conceituação, (ii) partiu-se a um estudo profundo a respeito da formação da linguagem, de como ela influencia na criação de uma visão de mundo e, de igual modo, como essa visão condiciona a percepção e interpretação dos fenômenos e dos seres. Para tanto, valemo-nos dos ensinamentos de Humboldt, presentes em sua antologia organizada por Werner Heidermann e Markus J. Weininge (2006), Edward Sapir (1963, 1969), Coseriu (1982), Gadamer (1998, 1999), Berkeley (1973), Lixa (2000) e, ainda, de uma palestra proferida em Yale, no ano de 2009, pelo professor Paul Fry; Para termo do estudo, de modo a tornar objetivas e práticas as teorias abordadas, (iii) analisou-se uma decisão do Supremo Tribunal Federal que disciplina a respeito da possibilidade de alteração do prenome no registro civil sem a necessidade de cirurgia de mudança de sexo: a ADI 4735, de 2018. Ruma-se, portanto, às complexas discussões brevemente expostas nesta introdução.

\section{O PROCESSO DIALÉTICO DE CONHECIMENTO E A AÇÃO DE CONCEITUAR}

Há muito se discute, no decurso do pensamento filosófico ocidental, sobre a possibilidade de conhecimento das coisas do mundo, naquilo que diz respeito à existência de uma verdade e à capacidade do sujeito de a apreender. De todo modo, a questão apresenta-se-nos sob a indagação: "Aquilo que pensamos e os conceitos que usamos para designar os objetos correspondem, de fato, àquilo que é (ou às coisas que são)?"

Com o propósito de aprofundar a discussão, traz-se a contribuição do filósofo alemão Johannes Hessen (1964), o qual salienta que há uma correlação mútua entre consciência e objeto; isto é, somente são o que são quando o são um para o outro. Em outros termos, apenas há consciência quando há objeto - pois não existe consciência vazia - e somente há objeto quando há consciência para o perceber. Aceita-se, portanto, a existência desse dualismo consciência-objeto, mas somente isso não basta; é preciso determinar qual a relação que um tem sobre o outro, ou seja, como acontece o processo de apreensão do objeto pela consciência. Nesse caminho, ensina-nos Hessen que: 
O conhecimento pode definir-se, por último, como a determinação do sujeito pelo objeto. Mas o determinado não é o sujeito pura e simplesmente; mas apenas a imagem do objeto nele. Esta imagem é objetiva, na medida em que leva em si os traços do objeto. Sendo distinta do objeto, encontra-se de certo modo entre o sujeito e o objeto. Constitui o instrumento pelo qual a consciência cognoscente apreende o seu objeto (HESSEN, 1964, p. 27).

Por esse raciocínio percebe-se que o processo de conhecimento acontece condicionado pelo objeto, o qual transcende o sujeito que observa; não de modo totalmente passivo, porém, pois há espaços de indeterminação - pela impossibilidade de apreensão total do objeto -, que são preenchidos pela própria consciência (HESSEN, 1964). ${ }^{1}$

Diametralmente adversa é a estrutura da ação de conceituação; esta parte do sujeito ao objeto e a ação é delimitadora. É aquilo que o sujeito percebe do objeto a partir dos traços deste, que emanam na forma de conceitos determinadores. Dentre vários caminhos de compreensão, fixa-se um: seja em relação aos objetos reais - inferidos da experiência -, seja naquilo que se refere aos ideais - meramente pensados. Dessa maneira, Hessen (1964, p. 29) ainda salienta que "o sujeito e o objeto não se esgotam no seu ser de um para o outro, pois têm além disso um ser em si mesmos", o qual escapa à consciência.

Por esse viés, o que aqui se apresenta como importante é a estrutura delimitadora da ação de conceituação. Assim escreveu Sartre de modo mais lírico: "falar é agir; uma coisa nomeada não é mais inteiramente a mesma, perdeu a sua inocência" (SARTRE, 2004, p. 20). Fê-lo de maneira a corroborar o entendimento de que a ação que parte do sujeito delimita o objeto, de maneira condicionada às percepções daquele.

Deste modo, conexa às questões concernentes ao conhecimento está a linguagem, pois é ela o meio e condição de possibilidade pela qual fluem as ideias e formam-se os conceitos. Debruçar-nos-emos, portanto, no seu estudo.

\subsection{O Lugar da Linguagem}

Assinalou-se, em breves termos, a estrutura do processo de conhecimento e, ainda, que seu oposto - a ação - atua de modo a circunscrever determinado objeto a um conceito. Cabe agora analisar o aspecto interpretativo, no qual se insere a linguagem; esta, enquanto extensão do pensamento, torna-se a parte substantiva da ação de conceituar, resultando na palavra, ${ }^{2}$ constituindo-se, assim, no meio pelo qual a compreensão dos fenômenos se torna possível e, ao mesmo tempo, no resultado desse encadeamento cognitivo.

Nas palavras de Michel Villey (2003, p. 27), "nenhum cientista conhece o homem, nem o cosmos, nem coisa alguma em sua concretude. Só apreende aspectos unilaterais das coisas, só manipula abstrações". É no sentido de tornar universal um conhecimento particular que se desenvolve a linguagem, na tentativa de compreensão do todo, ${ }^{3}$ de interpretação da imagem que se forma na consciência. Por conseguinte, "é verdade que as línguas das quais nos servimos e das quais somos prisioneiros (sistemas dos conceitos e dos termos mais gerais) constituem por si mesmas esboços de conhecimento universal; de estruturação do mundo" (VILLEY, 2003, p. 31-32).

Infere-se, pois, que o mundo apenas toma sentido a partir da linguagem; o conhecimento por si próprio não seria suficiente para expressar sentidos, significados, ideias, razão pela qual se erigiram os sistemas linguísticos, objetivando tornar universal ideias particulares, a fim de se possibilitar a comunicação e a cons-

\footnotetext{
Sendo o conhecimento uma determinação do sujeito pelo objeto, não há dúvida que o sujeito se conduz receptivamente perante o objeto. Esta receptividade não significa, contudo, passividade. Pelo contrário, pode falar-se de uma atividade e espontaneidade do sujeito no conhecimento. Esta não se refere, naturalmente, ao objeto no que a consciência pode muito bem participar, contribuindo para a sua elaboração. A receptividade perante o objeto e a espontaneidade perante a imagem do objeto no sujeito são perfeitamente compreensíveis (HESSEN, 1964, p. 27-28).

2 "Da imagem, a palavra distingue-se através da possibilidade de se imaginar a coisa nela subsumida sob vários ângulos e de diferentes formas; de uma mera alusão, a palavra distingue-se por sua própria forma sensorial determinada. Quem pronuncia a palavra nuvem não pensa em uma definição, tampouco em uma imagem específica desse fenômeno da natureza" (HUMBOLDT, 2006, p. 13). Frisa-se a distinção entre observar um objeto e pensar na palavra - fruto da ação de conceituação - que o representa. Tanto o conceito contido na palavra quanto a imagem formada na consciência, podem ser entendidos diferentemente.

3 “Portanto, a língua é, se não como um todo, pelo menos em termos sensoriais, o meio através do qual o homem constrói simultaneamente a si mesmo e ao mundo, ou melhor, através do qual se torna consciente de si mesmo, pelo ato de externar um mundo à parte, de dentro de si" (HUMBOLDT, 2006, p. 183).
} 
trução de uma visão de mundo. Premente é, neste momento, dedicarmos algumas linhas ao estudo da conformação social da língua, posto que é este o aspecto central naquilo que se refere à compreensão de como entendemos o mundo que nos envolve; compreensão, portanto, de como se estruturam as visões de mundo.

\section{LÍNGUA E CULTURA:}

\section{A Linguagem Enquanto Reflexo Cultural e Psicológico de uma Sociedade}

Intenta-se, por intermédio do estudo linguístico, buscar, também, um caminho para o estudo do comportamento humano, isto é, por meio da manifestação dos pensamentos, mediante a linguagem. $O$ ser humano externa ao mundo suas inclinações culturais e comportamentais. Desse modo, afirma Edward Sapir ser a língua um complexo de símbolos refletindo todo o quadro físico e social em que se acha situado um grupo humano (1969).

Por tal prisma, entende-se que as línguas representam realidades sociais, ou seja, o modo como determinadas sociedades em um dado tempo interpretam e interagem com o mundo. Sapir (1969) assevera que:

Os seres humanos não vivem apenas no mundo objetivo, nem apenas no mundo da atividade social como ela é geralmente entendida, mas também se acham em muito grande parte à mercê da língua particular que se tornou o meio de expressão da sua sociedade (p. 20).

Destarte, os interesses culturais marcam a ininterrupta formação da linguagem: as atribuições de significado - mais ou menos especificadas - são construídas por meio da concretização desses fatores psicológico-sociais. Assim, seguindo este entendimento, Sapir $(1969)$ corroborou a ideia de que o modo como interpretamos o mundo é condicionado pelos hábitos linguísticos, os quais predispõem certas escolhas de interpretação.

Sob essa perspectiva, vê-se que a atribuição de significados não acontece de modo desregulado, mas é, antes, direcionada por condições históricas e sociais. Em outros termos, o estudo das significações linguísticas - terminologias - permite uma nova compreensão da história das invenções e das ideias e de sua conformação cultural (SAPIR, 1969). Nesse sentido, Sapir (1069) enfatizou que "a melhor maneira de compreender psicologicamente a linguagem, ao que parece, é vê-la como um complicadíssimo exemplo de todo um conjunto de símbolos secundários, ou referenciais, que a sociedade fez surgir" (p. 23).

Dessa maneira, a língua, o ambiente e o ser humano estão imbricados em uma relação de contínua construção interpretativa que configura o modo de ver o mundo. Conforma, em última instância, o social, o psicológico e o histórico - formadores e condicionantes da consciência humana. Sob esse aspecto, entende-se, seguindo o abono de Sapir, ambiente como sendo um complexo de fatores físicos e sociais. Nas palavras do autor: Dividir o período realçado

[...] convém compreender no termo "ambiente" tanto os fatores físicos quanto os sociais. [...] Por fatores sociais se entendem as várias forças da sociedade que modelam a vida e o pensamento de cada indivíduo. Entre as mais importantes dessas forças estão a religião, os padrões éticos, a forma de organização política e a arte (1969, p. 44).

Os fatores sociais atuam de maneira a condicionar a formação da linguagem, sua interpretação e significação. Assim, em um processo de formação linguística acontece, de igual modo, a formação social e a conformação cultural de uma dada sociedade.-Segundo Sapir (1969), dá-se de modo condicionado pelos interesses coletivos - no sentido de que quando uma sociedade se propende a certas relações mais que a outras, esse fato é, também, refletido na formação lexical da língua. Dessa maneira e sob tais influências, a língua torna-se cada vez mais complexa - quanto mais complexas forem as relações dos indivíduos e seus interesses. Dispõe Sapir (1969), então, que: Dividir período

Tudo depende naturalmente do ponto de vista em que se coloca o interesse. Com isso no espírito, logo se compreende que a presença ou ausência de termos genéricos depende em grande parte do caráter positivo ou negativo do interesse que despertam os elementos ambientais correspondentes. Quanto mais necessário for para uma cultura fazer distinções dentro de uma dada série de fenômenos, tanto menos provável será a existência de um termo genérico para a série toda. Por outro lado, quanto mais culturalmente indiferentes forem esses elementos, tanto mais provável será que eles todos se englobem num termo único de aplicação geral (p. 47-48). 
Sob essa égide terminológica, compreende-se que a formação do léxico, refletindo o ambiente social, tem alcance no tempo e no espaço, isto é, os conceitos culturais e, de igual modo, o léxico a eles referente vão se tornando cada vez mais ricos e ramificados com o aumento da complexidade cultural (SAPIR, 1969).

O imbróglio que se nos apresenta tem início no momento em que a língua - enquanto reflexo das interações sociais - deixa de significar os novos movimentos ou entendimentos do corpo social. De tal sorte, as distinções e especificações do comportamento humano no social, pelo modo e velocidade com que surgem, não encontram amparo linguístico de conceitos que a eles correspondam - e, portanto, também não habitam, ainda, a consciência geral dos indivíduos. Para falar como Sapir (1969), a cultura torna-se mais complexa, mas há um interlúdio até a língua se tornar, da mesma forma, mais ramificada. A esse fenômeno chama-se momento de deriva.

\subsection{Momento de Deriva ${ }^{4}$}

Seguindo a construção teórica de Edward Sapir, o momento de deriva é caracterizado por um interlúdio na correspondência entre signos linguísticos - e seus significados - e a realidade social. Em outros termos, a língua perde a capacidade de, plena e fidedignamente, refletir o todo da realidade social. Esse fenômeno ocorre em virtude da diferença de processamento cognitivo entre dados culturais e linguísticos, isto é, os dados da língua são, necessariamente, menos suscetíveis de aflorar na consciência dos falantes do que os dados culturais (SAPIR, 1969). Isso significa, em termos práticos, que as mudanças culturais, por serem de mais fácil percepção e intensidade, ocorrem de modo anterior às mudanças linguísticas. ${ }^{5}$

Do mesmo modo, este momento, em que as mudanças sociais e culturais estão em pleno aflorar - enquanto fenômenos que se manifestam no tempo e espaço, circunstancialmente delimitados - e as formas linguísticas - léxico representativo de realidades em transformação - não mais abarcam a complexidade da mudança, foi, por Sapir (1969), chamado de momento de deriva.

Em outra obra, ${ }^{6}$ Sapir volta a se referir a esta ideia conceitual e agrega o fato de a deriva linguística ter como início variações individuais de fala e significação. A língua existe apenas dentro de sua aplicação - falada, ouvida e lida -, razão pela qual toda mudança que nela se verifica de modo significativo tem de existir, inicialmente, como variação individual. Assim, em relação ao exposto, enuncia:

A deriva da língua, ao contrário tem um rumo. Em outros termos, só a encarnam ou transportam aquelas variações individuais que se movem em certa direção, precisamente como são apenas certos movimentos das ondas na baía que marcam o avanço da maré. A deriva de uma língua consta da seleção inconsciente, feita pelos que a falam, das variações individuais que se acumulam numa dada direção especial (SAPIR, 1963, p. 124).

\footnotetext{
4 "[...] não só as palavras da língua passam a servir de símbolos de elementos culturais dispersos, como sucede nas línguas em qualquer período de desenvolvimento, mas se pode supor que as próprias categorias e processos gramaticais simbolizariam tipos correspondentes de pensamento e atividade de significação cultural. Até certo ponto, pode se conceber, portanto, a cultura e a língua em constante estado de interação e em associação definida por um largo lapso de tempo. Mas tal estado de correlação não pode continuar indefinidamente. Pela mudança gradual da psicologia coletiva e do ambiente físico há de se efetuar mudanças mais ou menos profundas tanto na língua como na cultura. Ora, a língua e a cultura não são evidentemente uma expressão direta da psicologia racial e do ambiente físico, senão que depende primariamente, para a sua existência e perenidade, das forças da tradição. Assim, apesar da necessidade de modificações numa e noutra com o correr do tempo, sempre se fará sentir uma tendência conservadora a refrear as tendências para a mudança. $\mathrm{E}$ aqui chegamos ao ponto crucial. Os elementos culturais, que servem de maneira mais definida às necessidades imediatas da sociedade e entram mais claramente no campo da consciência, não só hão de mudar mais rapidamente do que os elementos linguísticos, mas a própria forma da cultura, que dá a cada elemento a sua significação relativa, há de ficar num processo contínuo de remodelação [...] em outras palavras, a tendência conservadora se faz sentir muito mais profundamente nos lineamentos essenciais da língua do que na cultura. Daí a consequência necessária de que as formas da língua, com o correr do tempo, deixarão de simbolizar as da cultura, o que é a nossa tese central" (SAPIR, 1969, p. 60-61).

5 " [...] as mudanças na cultura provêm, pelo menos em grande parte, de processos conscientes ou de processos que facilmente se tornam conscientes, ao passo que as da língua se devem explicitar, se é que se explicitam, como devidas a uma ação mais sutil de fatores psicológicos que escapam ao domínio da vontade e da reflexão" (SAPIR, 1969, p. 59).

6 SAPIR, Edward. A linguagem. 2. ed. São Paulo: Ed. Perspectiva, 1963.
} 
Pode-se, portanto, inferir essa direção por intermédio do passado histórico da língua (SAPIR, 1963), perspectiva pela qual se evidencia que faz parte do processo de formação linguístico a transformação cultural enquanto motor que impulsiona tal mudança.

É sob essa égide teórica que se busca, neste momento, a compreensão do processo comunicativo como formador (dinâmico) dos modos linguístico-conceituais. Em outros termos, a possibilidade de construção linguística é calcada em condições culturais e históricas como visto, mas, também, como parte constituinte e resultante do próprio falar.

\section{LINGUAGEM EM MOVIMENTO: Reestruturação de Conceitos e Interesses Linguístico-Sociais}

Parte-se da premissa primeira de que a linguagem acontece sempre direcionada a alguém como meio necessário e possibilidade de comunicação. ${ }^{7}$ A partir disso, concebe-se o processo de comunicação como possibilidade, isto é, escolha de conceitos que permitam o entendimento sobre aquilo que se fala - e não como forma fixa da língua ou representação de sua essência. Não se trata, então, da linearidade da linguagem, mas, sim, dos fins aos quais se propõe o ato de falar (COSERIU, 1982).

Assim sendo, a linguagem assume um aspecto de movimento - no sentido de constante construção e modificação permanente de seus conceitos e significados - por intermédio do ininterrupto processo de comunicação. Coseriu, seguindo a teorização de Friedrich Wilhelm Christian Karl Ferdinand, barão von Humboldt, ${ }^{8}$ identifica essa ideia de movimento linguístico no conceito de enérgeia. Dispõe, então, que, "com a determinação da linguagem como enérgeia, chegamos a um ponto decisivo. A linguagem é agora para nós uma atividade livre. Pertence, pois, ao que é propriamente humano" (COSERIU, 1982, p. 24).

Por essa razão, a linguagem não determina fixos significados; antes, porém, manifesta uma possibilidade de interpretação do real - em outros termos, dentro de um processo comunicativo dinâmico, representa, ela, a linguagem, uma escolha. Do mesmo modo, o meio de individualização dos conceitos acontece mediante uma ação secundária, isto é, a partir de um conceito geral e já existente na língua, que se pode nomear, ou seja, tornar particular uma ideia geral. Coseriu assinala que:

O significado, pois, implica apenas a possibilidade do "ente" - um "ser tal e qual" -, e não o próprio ente. Só secundariamente pode chegar a linguagem à designação do ente através do "ser tal e qual". O "ser árvore" é primário e a aplicação às arvores, aos entes que correspondem a esse modo de ser, é um fato secundário. Mas a mera possibilidade é algo universal; por isso, somente através duma operação secundária de individualização, a partir do universal, a linguagem pode chegar à designação dos exemplos particulares do "ser tal e qual". Também as designações individuais historicamente fixadas - os "nomes próprios" - são, a esse respeito, um fenômeno secundário que pressupõe apreensão do universal (existem nomes próprios apenas para entes já nomeados mediante apelativos, e não ao contrário (COSERIU, 1982, p. 27).

A essa concepção de linguagem coaduna-se, como visto, o entendimento de que nenhum tipo de significação linguística é neutro - do ponto de vista daquele que nomeia e o contexto cultural no qual se insere -, e nem fixo - a partir da possível aceitação de que a linguagem seria estática. Por esse viés, segue-se na análise teórica de linguagem enquanto representação do todo fenomênico e como possibilidade de compreensão.

"[...] a linguagem como falar é um falar com o outro. Isso já distingue a linguagem das demais atividades expressivas, que não se dirigem necessariamente a outro ser (ainda que, naturalmente, o "outro" possa acolher e interpretar a expressão e determinar a sua própria conduta com base no que interpretou; a chamada "comunicação" dos animais pertence em grande parte a esse tipo: na verdade, não se comunica nada, o animal é que ajusta a sua reação a uma outra reação, interpretada" (COSERIU, 1982, p. 18).

8 "A língua em si não é uma obra acabada (Ergon), mas sim uma atividade (Energeia). Por isso sua verdadeira definição só pode ser aquela que a apreenda em sua gênese. Afinal a língua consiste no esforço permanentemente reiterado do espírito de capacitar o som articulado para e expressão do pensamento" (HUMBOLDT, 2006, p. 99). 


\subsection{Humboldt e a Cosmovisão Linguística: \\ a contribuição para a discussão sobre a alteração do prenome no registro civil}

Os ensinamentos deixados por Humboldt são de extrema relevância para a compreensão daquilo que representa a linguagem no processo de formação do ser humano e de sua civilização. É por essa razão que, neste momento, recorre-se a ele: porque, apesar de os estudos jurídicos buscarem as certezas da e na lei, é do estudo profundo do social e daquilo que nele está envolto que decorrem as explicações, justificações e interrogações para com aquilo que está positivado. Em outros termos, esta pesquisa tem por objetivo o estudo da possibilidade de se legiferar sobre a alteração civil do prenome, porém não nos parece justo fazê-lo sem trazer ao debate o como e o porquê de este fenômeno social estar acontecendo. É nesse sentido que Humboldt nos auxilia ao teorizar a respeito de uma visão de mundo integral, isto é, de modo a envolver o Homem, a Linguagem e o Universo.

Assim, a língua torna-se o próprio objeto de análise, e, de certo modo, possibilita também a análise da formação do homem enquanto ser humano - conjuntamente a tudo que esse conceito implica - e suas possibilidades de entendimento do mundo. Dessa forma, a visão Holística (entendimento integral) constitui-se da consideração de uma perspectiva triangular de Homem, Linguagem e Universo. Considerações, portanto, de como o homem forma a língua e de como a língua forma o homem, percebendo-se, assim, como a interação desses elementos possibilita e condiciona o entendimento das coisas do mundo. Concretiza-se, por esse viés, a concepção de linguagem não apenas como meio de comunicação objetiva, mas como ente formador de caráter e possibilidade de assimilação de fenômenos complexos manifestados e apresentados ao intelecto humano (HUMBOLDT, 2006).

Destarte, como já citado, o movimento do social condiciona a formação da linguagem e, ao mesmo tempo, a linguagem condiciona a formação do social. Ao se pensar, todavia, na possibilidade de alteração de um prenome, vê-se por detrás dessa situação um contexto cultural no qual determinadas peças da linguagem - os nomes - são aceitas e outras não; um contexto cultural apregoado às formas fixas da língua e que, ao se deparar com o diferente, espanta e busca auxílio no direito. Nessa perspectiva:

O organismo das línguas nasce da capacidade e da necessidade geral do ser humano de falar, e descende de toda a Nação; a cultura de cada língua depende de disposições e destinos particulares, e repousa, em sua maior parte, sobre os indivíduos que vão surgindo na nação aos poucos. O organismo faz parte da fisiologia do ser humano intelectual, e a formação faz parte da série de desenvolvimentos históricos. O desmembramento das diferenças do organismo leva à medição e ao exame da região da língua e da capacidade humana da linguagem; a investigação na condição de uma formação cultural mais elevada conduz ao reconhecimento da consecução de todos os objetivos humanos por meio da linguagem (HUMBOLDT, 2006, p. 38-39).

Assim sendo, as escolhas referentes às formas linguísticas refletem, em última instância, uma opção de interpretação do mundo. No caso ora estudado, para exemplificar, escolher que certos nomes são aceitos para determinadas pessoas e não para outras, reflete uma visão de mundo ocidental, mais especificamente latina, e, mais ainda, brasileira, que poderia, também, especificar-se mais quanto mais restrita fosse a cultura analisada. ${ }^{9}$ Segundo Humboldt (2006),

[...] a língua não é um livre produto do ser humano singular, mas pertence sempre a toda a nação; também nesta, as gerações mais recentes recebem a língua lá das gerações anteriores. Pelo fato de que nela o modo de representação de todas as idades, sexos, estamentos, diferenças de caráter e de espírito - da mesma tribo, e, então por meio da transição de palavras e línguas de diferentes nações em crescente comunidade de todo o gênero humano, por fim - mistura-se, apura-se e ganha outra conformação, a língua torna-se o grande ponto de transição entre a subjetividade e a objetividade, entre a subjetividade sempre limitada e a existência que tudo abarca simultaneamente em si (p. 71-73).

\footnotetext{
"Através da dependência recíproca do pensamento e da palavra fica evidente que as línguas na verdade não são meios para a representação da verdade conhecida, mas sim muito mais para a descoberta do anteriormente desconhecido. A sua diferença não reside nos sons e signos, mas na diferença de concepções de mundo em si" (HUMBOLDT, 2006, p. 77).
} 
Entendendo, pois, que a formação social e a linguística estão imbricadas desde o nascedouro e que, em certos aspectos, deixam, mutuamente, marcas umas nas outras, percebe-se que a interpretação, seja de nomes ou de seres, não acontece ao acaso; razão pela qual se torna árduo o trabalho de estudar a situação que passamos hodiernamente, isto é, momento em que as relações sociais se modificam em velocidade extrema e que, quando obstaculizadas, procuram no Direito um caminho a seguir. É por esse motivo que se deve buscar nos estudos linguísticos um auxílio para o entendimento do que significa um nome, qual a força simbólica que nele é posta e de que forma isso reflete um contexto cultural. Desse modo, até este momento adentrou-se nas teorizações a respeito da língua, dos significados e de suas variações; cabe, agora, o estudo da interpretação dessa peça da língua - o nome - e a atribuição dele a um ser histórico - uma pessoa, circunscrita por seu tempo e por sua cultura.

\section{CÍRCULO HERMENÊUTICO E A INTERPRETAÇÃO DE SERES HISTÓRICOS}

Aquilo que foi até aqui abordado será, pelos autores citados neste tópico, entendido como "pré-compreensões". Em outros termos, a bagagem histórica - que envolve língua e cultura - que trazemos possibilita e, ao mesmo tempo, condiciona o modo como assimilamos os fenômenos do mundo. Viu-se a magnitude das influências da linguagem na formação social e, dessa forma, entendeu-se que nos portamos no universo imersos em um mar de significados, os quais, ao longo do tempo, foram forjados culturalmente. Neste momento, parte-se ao estudo de como essa bagagem influencia na nossa interpretação dos nomes e das pessoas que os usam.

Por esse viés, a definição de círculo hermenêutico é dada a partir da relação entre horizontes históricos, que podem ser definidos pelo local no tempo e espaço em que se situa o ente ao qual se interpreta. O Ser que se situa e representa determinado horizonte histórico foi, por Heidegger (2006), denominado de Dasein. A esse respeito, Gadamer (1999) assevera:

A analítica temporal da existência (Dasein) humana, que Heidegger desenvolveu, penso eu, mostrou de maneira convincente que a compreensão não é um modo de ser, entre outros modos de comportamento do sujeito, mas o modo de ser da própria pré-sença (Dasein). O conceito "hermenêutica" foi empregado, aqui, nesse sentido. Ele designa a mobilidade fundamental da pré-sença, a qual perfaz sua finitude e historicidade, e a partir daí abrange o todo de sua experiência de mundo. Que o movimento da compreensão seja abrangente e universal não é uma arbitrariedade ou uma extrapolação constitutiva de um aspecto unilateral, mas está, antes, na natureza da própria coisa (p. 16).

Quando Gadamer afirma que a compreensão é o próprio modo de ser do ser-aí, reitera a noção de o homem estar mergulhado na linguagem que interpreta, por meio de seus preconceitos, a todo instante. Especificamente a respeito do círculo hermenêutico, o professor Paul H. Fry (FRY, 2009) explica:

Eu me aproximo de um texto e a primeira coisa que leio é uma frase. Ainda há muito mais texto. Isto é apenas uma parte. Mas eu, imediatamente, começo a formar uma opinião sobre essa parte em relação a um todo imaginado ou suposto. Então, uso esse sentimento do que deve ser o todo ao continuar lendo partes sucessivas. E mantenho a referência das partes sucessivas com a idéia desse todo que muda como resultado desse crescente conhecimento. A circularidade deste vínculo com a interpretação tem a ver com o movimento de ir e vir entre essa certa pressuposição sobre o todo que eu formei a partir do estudo de uma parte movendo-se então à parte, de volta ao todo e assim por diante, em um padrão circular.

Desse modo, tal circularidade é marcada pelo confronto de horizontes históricos. A expansão do círculo hermenêutico que é, neste trabalho, sugerida, intenta visar o confronto de seres com formações culturais distintas em um mesmo horizonte histórico. Ao transpassar tal pensamento à interpretação de nomes, chega-se a tal postulado: por uma peça de linguagem que representa a ideia de determinado ser cognitivo - o nome - o intérprete idealiza esse ser mediante as suas pré-compreensões históricas. ${ }^{10}$ Deixa-se de lado o objetivo pri-

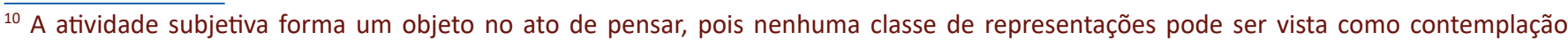
meramente receptiva de um objeto já existente. A atividade dos sentidos há de se unir numa síntese com a ação interior do espírito e, desta união, depreende-se a representação, que, ante a força subjetiva torna-se objeto e, novamente percebido como tal, retorna àquela (HUMBOLDT, 2006, p. 131).
} 
meiro do ato de nomear que, como explicitado anteriormente, é a capacidade de distinção de seres em uma sociedade, para, por meio dos preconceitos, tachar o ser e imbricá-lo, inevitavelmente, à imagem que se espera que ele represente - entenda-se que essa expectativa de representação é formada cognitivamente em determinada sociedade por intermédio de sua formação histórica: um homem é representado de determinada maneira e a ele cabe certos nomes; essa é uma ideia construída e não uma ideia daquilo que de fato ele o é.

Conforme o ensinado por George Berkeley ${ }^{11}$ (1973), o que ora tratamos como "expectativa de representação" é o resultado da tentativa de abstração das ideias sobre as coisas do mundo. Como já citado, tudo aquilo que parte do espírito humano - seja enquanto expectativa, seja enquanto modo de compreensão - é formado socialmente e, portanto, pode se modificar. Exemplo disso - e situação pela qual passamos - é a ideia de homem e de mulher. São conceitos gerais que, segundo preconceitos, particularizam-se, mas que, em última análise, não estão blindados às alterações.

Pelas teses abordadas até aqui infere-se, a respeito da interpretação de seres históricos, que ela se dá condicionada por fatores linguísticos - significados e símbolos formados ao longo dos tempos e das culturas e que se leva a termo tendo como base ideias gerais de fenômenos particulares - estas, também, construídas no seio de cada sociedade. Na prática, imagina-se o que deva representar um homem e uma mulher, e a essas ideias fixam-se determinadas peças linguísticas aceitas como normais. A partir disso, interpreta-se o nome, a pessoa e aquilo que ela representa. O que queremos mostrar com este trabalho é que nada disso é invariável ou inalterável. Por este viés, entende-se a necessidade de reconsiderar as tradições que impulsionam o ser a tomar determinado ato interpretativo como único e verdadeiro dentre todos os demais, pois, como afirma Gadamer (1998):

A consciência histórica já não escuta beatificamente a voz que lhe chega do passado, mas, ao refletir sobre si mesma, recoloca-a no contexto em que ela se originou, a fim de ver o significado e o valor relativos que lhe são próprios. Esse comportamento reflexivo diante da tradição chama-se interpretação" (p. 18-19).

No intento, portanto, de iluminar as teorias supracitadas calcando-se na realidade, traz-se à baila uma decisão do Supremo Tribunal Federal que versa sobre o tema ora tratado.

\section{JURISPRUDÊNCIA - Análise da Ação Direta de Inconstitucionalidade 4275 do Supremo Tribunal Federal}

Com base naquilo que foi estudado neste trabalho, concretizam-se tais teses a partir da análise de um caso concreto. Citar-se-á, portanto, uma decisão do Supremo Tribunal Federal proferida em 2018, a qual possibilitou a alteração do prenome e do sexo, no registro civil, por parte dos transgêneros sem a necessidade de cirurgia de mudança de sexo ou de tratamento hormonal.

O acórdão dispõe que:

O Tribunal, por maioria, vencidos, em parte, os Ministros Marco Aurélio e, em menor extensão, os Ministros Alexandre de Moraes, Ricardo Lewandowski e Gilmar Mendes, julgou procedente a ação para dar interpretação conforme a Constituição e o Pacto de São José da Costa Rica ao art. 58 da Lei 6.015/73, de modo a reconhecer aos transgêneros que assim o desejarem, independentemente da cirurgia de transgenitalização,

\footnotetext{
11 "[...] a fonte dessa noção privilegiada parece-me ser a linguagem. Certamente nada menos do que a razão poderia ter dado origem a uma opinião universalmente aceita. Vê-se isto, além de outras razões, na clara confissão dos mais competentes defensores das idéias abstratas que as reconhecem devido à necessidade de denominar; de onde a conseqüência clara: se não houvesse o discurso ou os sinais universais, não teria havido idéia de abstração. Vejamos como as palavras contribuem para esse erro. Primeiro, pensa-se que cada nome tem ou deve ter um só significado definido e preciso, que leva o homem a pensar que há certas idéias abstratas determinadas constitutivas da verdadeira e única significação de cada nome geral; e só por intermédio dessas idéias abstratas pode um nome geral significar uma coisa particular. Pelo contrário, não há significação precisa e definida ligada ao nome geral, todos eles próprios para significar indiferentemente grande número de idéias particulares. Isto decorre evidentemente do que ficou dito e uma breve reflexão o põe claro. Pode objetar-se que cada nome definível está por isso mesmo restringido a certa significação. Por exemplo, o triângulo define-se 'uma superfície limitada por três linhas retas' e por este nome denota-se uma certa idéia e não outra. A isto respondo que na definição não se diz se a superfície é grande ou pequena, branca ou preta, se os lados são longos ou curtos, iguais ou desiguais, nem os ângulos segundo os quais se inclinam; em tudo pode haver grande variedade, e portanto nenhuma idéia determinada limita a significação da palavra triângulo. Uma coisa é manter constante definição de um nome, outra é fazer que ele represente sempre a mesma idéia; uma é necessária, outra é inútil e impraticável" (BERKELEY, 1973, p. 16). Valemo-nos deste ensinamento para assinalar que a ideia geral de homem e de mulher pode representar várias significações e que, desse modo, essa concepção é construída social e historicamente.
} 
ou da realização de tratamentos hormonais ou patologizantes, o direito à substituição de prenome e sexo diretamente no registro civil. Impedido o Ministro Dias Toffoli. Redator para o acórdão o Ministro Edson Fachin. Presidiu o julgamento a Ministra Cármen Lúcia. Plenário, 1ํ.3.2018 (BRASIL, 2018).

Busca-se, neste momento, identificar na referida decisão traços das teorias apresentadas nesta pesquisa. Em um primeiro contato, é de causar estranheza o fato de um ser humano ter de alterar seu prenome em razão de uma mudança de sua aparência - enquanto manifestação e representação no mundo. A partir, porém, do momento em que se identificam os elementos sociais que condicionam a interpretação e compreensão das coisas do universo e, com isso, entende-se que, como o apresentado por Humboldt (2006), o ser humano, sua linguagem e o universo no qual vive estão conectados, percebe-se que os conceitos arraigados na cultura e refletidos na língua são difíceis de serem alterados. Com isso, queremos salientar que a construção social do ser humano, do gênero e da linguagem está definida dentro de parâmetros considerados normais pela sociedade brasileira. Daí decorre a necessidade de alteração do prenome quando se muda de sexo, não pela necessidade linguística, pois, como visto, a língua é dinâmica e poderia se adaptar à nova conformação social, mas, antes, por um status quo de não aceitação dessa mudança. Isso, no entanto, não significa que sempre será assim.

A citada decisão da suprema corte brasileira, na falta de legislação adequada, visa a sanar um desacordo entre o social e o linguístico, como já apresentado por Sapir (1969), quando teorizou sobre o momento de deriva, isto é, quando as mudanças sociais ocorrem de tal forma que alguns conceitos linguísticos se tornam defasados, ou seja, não representam mais, de maneira correta, os fenômenos que se pretendiam representar.

Ademais, infere-se que acertada é a decisão judicial, posto que o cenário social pelo qual passa o Brasil gera desconforto àqueles que estão à frente das mudanças - naquilo que diz respeito às desconstruções pleiteadas na área dos gêneros. Assim, para termo deste estudo, frisa-se que vivemos em um mundo imerso em significados e símbolos que, antes de tudo, foram criados pelo espírito humano. Em outros termos e pelo que foi aqui exposto, sempre há de existir a capacidade humana de transformar o social e, com isso, o linguístico, a fim de remodelar conceitos e significar novas relações e estados do ser, a fim de, em última instância, tentar tornar completa a experiência da vida no social. Deve-se, então, sempre repensar o impulso histórico que nos move, como bem-assenta Ivone Lixa (2000):

Assim, o sentido de algo, seja um texto ou obra de arte, é definido pelos questionamentos postos pelo presente, cujos preconceitos herdados pela tradição devem estar abertos em relação ao novo, para que, fenomenologicamente, ocorra a revelação do que insiste em ser ocultado (p. 63).

Premente, portanto, é a situação em que vivemos - um momento de deriva linguística que afeta as relações sociais sob sua égide. De igual magnitude e intensidade, porém, se mostra a capacidade humana para a mudança e para a redescoberta de novos conceitos, novas relações, novas visões de mundo.

\section{CONCLUSÃO}

Sob a égide das teorias expostas nesta pesquisa e tendo sempre como parâmetro o quadro social brasileiro, chega-se a algumas considerações a respeito das mudanças sociais vividas no país. Buscou-se amparo na filosofia da linguagem, nas teorias linguísticas e na jurisprudência nacional para tentar abordar, de forma mais ampla e completa possível, o fenômeno de alteração do prenome, suas causas e explicações.

Possibilitou-se o entendimento da complexidade envolta neste processo, em que não estão envolvidas apenas questões jurídicas, mas, antes, todo um quadro de evolução social, civilizatória e linguística.

Em um primeiro momento verificou-se que $o$ ato de dar nomes às coisas traz consigo um forte teor simbólico; não sendo apenas um ato neutro, mas um fenômeno condicionado por diversos fatores: históricos, culturais, linguísticos, psicológicos... Nesse sentido, possibilita-se a compreensão destes significados apenas quando se considera o referido contexto no qual se formam.

Assim, ao nos aprofundarmos nas questões referentes à linguagem, observamos que ela, enquanto produto da consciência humana, traduz nos seus conceitos a realidade social na qual se formou, e isso dá a ela um aspecto de movimento, de transformação, uma vez que realidades sociais, de igual modo, modificam-se. 
O problema tem início quando as formas da língua deixam de adequar-se ao momento histórico pelo qual passa determinada sociedade. No nosso entender, este é o caso brasileiro: isto é, as alterações nas concepções de gênero representam uma realidade social, porém a ideia de que na língua essa alteração também é possível não foi assimilada pela sociedade. Em outros termos, ainda persiste a noção de que alguns nomes são do gênero masculino enquanto outros são do feminino, apesar de existir a possibilidade de se escolher outro caminho interpretativo.

Como visto, esse fato é justificado pelo processo de formação da língua e do imaginário brasileiro, e é por tal motivo que se torna premente tal regulamentação. $O$ fato de o imaginário abstrato da sociedade brasileira estar fixado em determinados parâmetros conceituais, faz com que os que disso destoam - aqueles que alavancam a referida mudança nas relações sociais - tornem-se vítimas de discriminação. Em uma tentativa de adequar-se aos moldes exigidos socialmente, muda-se o nome. Não precisaria ser assim, não será sempre assim, porém, neste cenário em que ávidas são as alterações na estrutura social, premente é o auxílio jurídico para tornar possível o bem-estar no social.

\section{REFERÊNCIAS}

BRASIL. Supremo Tribunal Federal. Ação Direta de Inconstitucionalidade: ADI 4725 - 1/600. Brasília: STF, 2018.

BERKELEY, George. Tratado sobre os princípios do conhecimento humano. São Paulo: Ed. Abril Cultural e Industrial, 1973. 44 p. COSERIU, Eugênio. O homem e sua linguagem: estudos de teoria e metodologia linguística. São Paulo: Presença, 1982.

FRY, Paul H. Introdução à teoria da literatura. YouTube, New Haven, 2009. On-line. Disponível em: https://www.youtube.com/ watch?v=akm1kgfbyx4.

GADAMER, Hans-Georg. Verdade e método - traços fundamentais de uma hermenêutica filosófica. Petrópolis: Ed. Vozes, 1999. $736 \mathrm{p}$.

GADAMER, Hans-Georg. O problema da consciência histórica. São Paulo: Ed. Fundação Getúlio Vargas, 1998. 72 p. HESSEN, Johannes. Teoria do conhecimento. Coimbra: Arménio Amado, 1964. 206 p.

HUMBOLDT, Alexander von. Humboldt: linguagem, literatura, bildung. Org. Werner Heidermann e Markus Weininge. Florianópolis: UFSC, 2006. $268 \mathrm{p}$.

LIXA, Ivone. A possibilidade de revisão da hermenêutica jurídica tradicional a partir de elementos da hermenêutica filosófica de Hans-Georg Gadamer. 2000. Dissertação (Mestrado em Concentração de Filosofia e Teoria do Direito) - Universidade Federal de Santa Catarina, Curso de Pós-Graduação em Direito, 2000.

SAPIR, Edward. A linguagem. 2. ed. São Paulo: Ed. Perspectiva, 1963.

SAPIR, Edward. Linguística como ciência. Rio de Janeiro: Ed. Livraria Acadêmica, 1969.

SARTRE, Jean Paul. O que é literatura. São Paulo: Ed. Ática, 2004. 256 p.

VILLEY, Michel. Filosofia do direito. Definições e fins do direito. Os meios do direito. 1. ed. São Paulo: Martins Fontes, 2003.464 p. 